See Article page XXX.

\section{Commentary: Left ventricular assist device implantation and failure to rescue: New insights and familiar challenges}

\author{
Maxwell F. Kilcoyne, DO, Walker M. Blanding, MD, \\ and Arman Kilic, MD
}

Advancements in left ventricular assist device (LVAD) technology have improved outcomes; however, adverse events continue to influence survival and quality of life in this patient population. The incidence of postoperative complications after LVAD implantation is similar across centers nationwide, but in-hospital mortality varies significantly. Pienta and colleagues ${ }^{1}$ aim to address the role of failure to rescue (FTR), or in-hospital mortality after a major complication, in the mortality variation seen after LVAD implantation. ${ }^{1}$

Making use of the Society of Thoracic Surgeons Interagency Registry for Mechanically Assisted Circulatory Support database, more than 13,000 patients at 131 hospitals were examined for differences in in-hospital outcomes. Mortality variation was significant among centers, with a 3.1-fold difference between low and high-mortality terciles. When comparing the mortality terciles, there was only a 1.1 -fold difference in complications but a 2.8 -fold difference in FTR. The authors found significant differences in FTR rates after all major complications, except for stroke, among center mortality terciles. The authors suggest these results are due to differences in identification and/or management of complications among centers and play a significant role in reducing subsequent mortality. This is not the first analysis to demonstrate the importance of FTR after cardiac surgery; similar trends have been demonstrated for postoperative management of coronary artery bypass

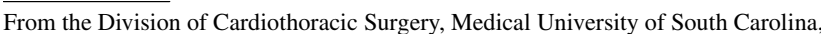
Charleston, SC.

Disclosures: Dr Kilic is a speaker and consultant for Abiomed and Abbott. All other authors reported no conflicts of interest.

The Journal policy requires editors and reviewers to disclose conflicts of interest and to decline handling or reviewing manuscripts for which they may have a conflict of interest. The editors and reviewers of this article have no conflicts of interest.

Received for publication Nov 8, 2021; revisions received Nov 8, 2021; accepted for publication Nov 9, 2021.

Address for reprints: Arman Kilic, MD, Division of Cardiothoracic Surgery, Medical University of South Carolina, 30 Courtenay Dr, MSC 295, Suite BM279, Charleston, SC 29425 (E-mail: kilica@musc.edu).

J Thorac Cardiovasc Surg 2021; $\mathbf{\square}: 1-2$

$0022-5223 / \$ 36.00$

Copyright (C) 2021 Published by Elsevier Inc. on behalf of The American Association for Thoracic Surgery

https://doi.org/10.1016/j.jtcvs.2021.11.011
}

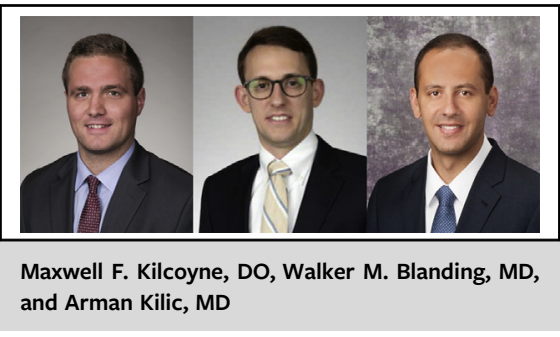

CENTRAL MESSAGE

Failure to rescue after LVAD implantation is a significant contributor to short-term mortality. Early complication recognition and appropriate clinical response is critical for improving outcomes.

grafting, aortic valve, and mitral valve interventions. ${ }^{2-4}$ This is corroborated by noncardiac surgery literature that has also identified institutional characteristics associated with decreased FTR; this includes intensive care unit coverage with higher intensivist-, nurse-, and resident-topatient ratios and a dedicated rescue response team. ${ }^{3,5}$ Given the preoperative and postoperative physiology and tenuous state of patients with end-stage heart failure, it is not surprising that FTR comes at a high cost for this patient population, perhaps more so than lower-risk patients.

The authors also found that LVAD high-volume centers treated significantly higher-risk patients and experienced higher rates of complications. However, higher-volume centers did demonstrate an overall lower incidence of FTR. Although theoretical, this may relate to staff being more experienced in managing these patients with complex disease and institutional practices that lead to early recognition and mitigation of these complications. Resource availability is also an important factor to consider for varying rates of FTR. It is becoming increasingly evident that reducing FTR is a resource-intensive endeavor. Low-volume and safety-net hospitals are particularly vulnerable to the costs of FTR secondary to limited resources, potentially inexperienced staff, and a challenging patient population. ${ }^{6}$ As FTR becomes a more established quality metric, it will be crucial that these factors are taken into consideration when assessing hospital performance and/or quality improvement.

Pienta and colleagues ${ }^{1}$ have identified a critical area for improvement in LVAD outcomes. FTR is a complex issue 
that particularly influences these high-risk patients. The data suggest that adequate staffing and appropriate clinical response to complications that arise can save patient lives, even in populations deemed high-risk. The next stage of utilizing the FTR quality metric is in identifying specific complication identification and management strategies to optimize patient care.

\section{References}

1. Pienta M, Cascino TM, Likosky DS, Ghaferi AA, Aaronson KD, Pagani FD, et al. Failure to rescue - a candidate quality metric for durable left ventricular assist device implantation. J Thorac Cardiovasc Surg. 2022;XX:XX-XXX.
2. Kurlansky PA, O’Brien SM, Vassileva CM, Lobdell KW, Edwards FH, Jacobs JP, et al. Failure to rescue: a new Society of Thoracic Surgeons quality metric for cardiac surgery. Ann Thorac Surg. July 6, 2021 [Epub ahead of print].

3. Reddy HG, Shih T, Englesbe MJ, Shannon FL, Theurer PF, Herbert MA, et al. Analyzing "failure to rescue": is this an opportunity for outcome improvement in cardiac surgery? Ann Thorac Surg. 2013;95:1976-81.

4. Edwards FH, Ferraris VA, Kurlansky PA, Lobdell KW, He X, O’Brien SM, et al. Failure to rescue rates after coronary artery bypass grafting: an analysis from the Society of Thoracic Surgeons Adult Cardiac Surgery Database. Ann Thorac Surg. 2016;102:458-64.

5. Ward ST, Dimick JB, Zhang W, Campbell DA, Ghaferi AA. Association between hospital staffing models and failure to rescue. Ann Surg. 2019;270:91-4.

6. Sanaiha Y, Rudasill S, Sareh S, Mardock A, Khoury H, Ziaeian B, et al. Impact of hospital safety-net status on failure to rescue after major cardiac surgery. Surgery. 2019;166:778-84. 